\title{
Involvement of sphingoid bases in mediating reactive oxygen intermediate production and programmed cell death in Arabidopsis
}

Lihua Shi ${ }^{1,2, *}$, Jacek Bielawski ${ }^{3,}$, Jinye $\mathrm{Mu}^{1,2, *}$, Haili Dong ${ }^{1,2}$, Chong Teng ${ }^{1,2}$, Jian Zhang ${ }^{1}$, Xiaohui Yang ${ }^{1}$, Nario Tomishige ${ }^{4}$, Kentaro Hanada ${ }^{4}$, Yusuf A Hannun ${ }^{3}$, Jianru Zuo ${ }^{1}$

Cell Research (2008) 18:324. doi: 10.1038/cr.2008.22; published online 4 February 2008

Correction to: Cell Research (2007) 17:1030-1040. doi: 10.1038/cr.2007.100; published online 4 December 2007

In the print version of this article, there is an error in the internal page number which located in the first page of this article. "Cell Research (2007) 17:1030-11040." should be "Cell Research (2007) 17:1030-1040.”. 